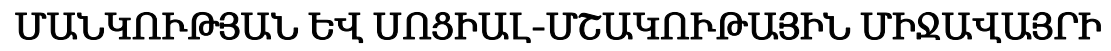

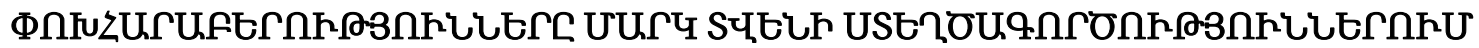

ᄂU.9UR3Uน L. Z.

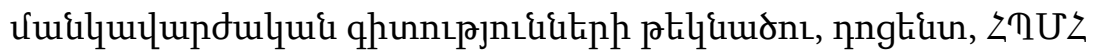

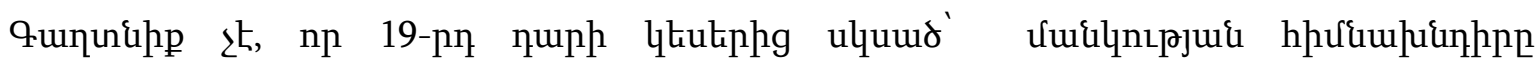

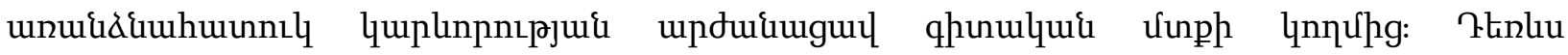

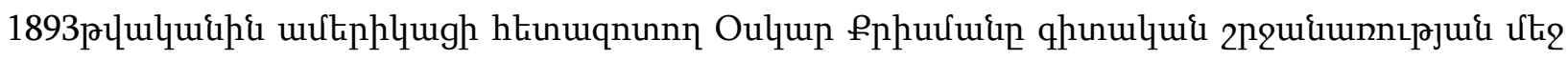

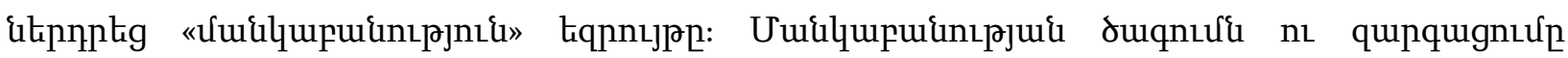

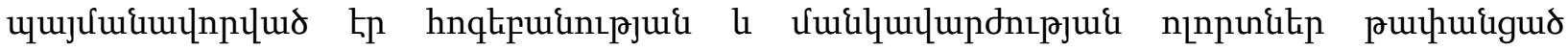

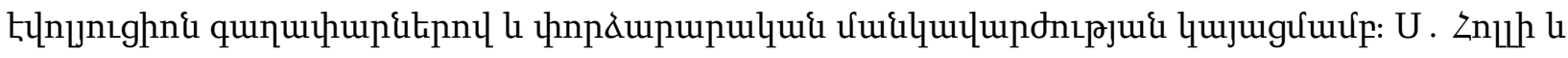

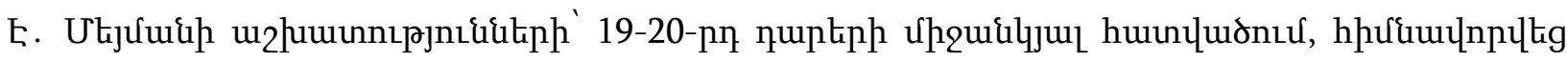

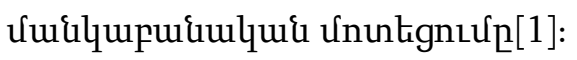

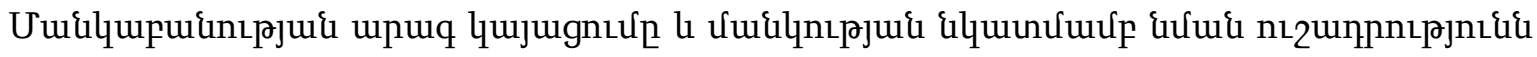

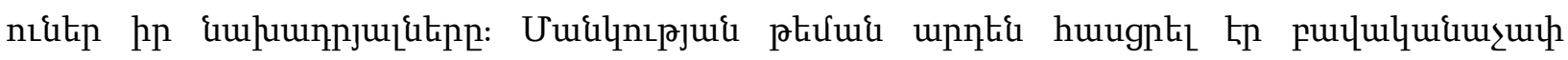

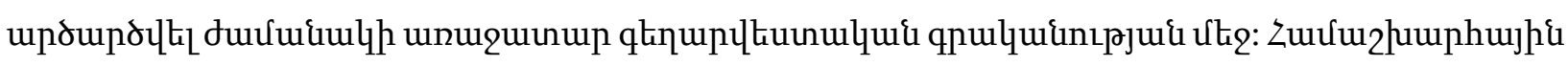

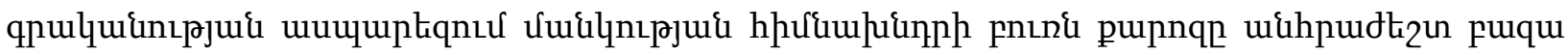

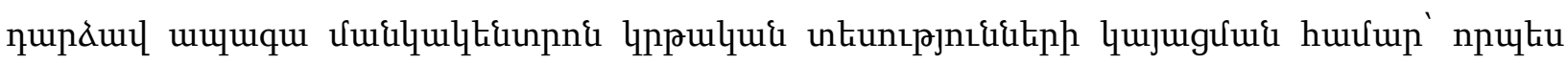

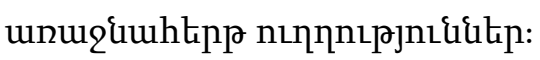

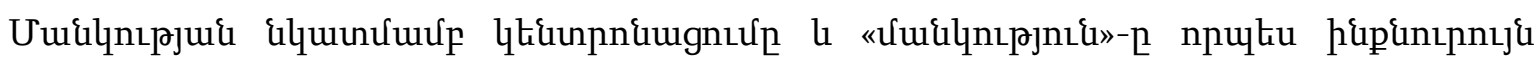

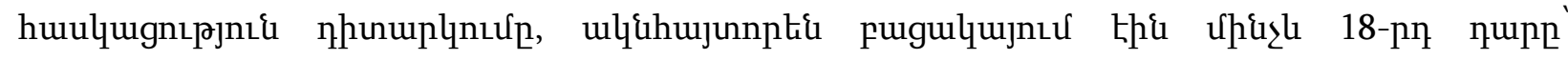

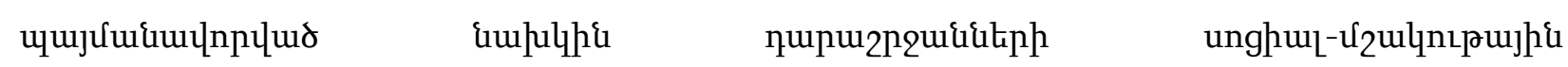

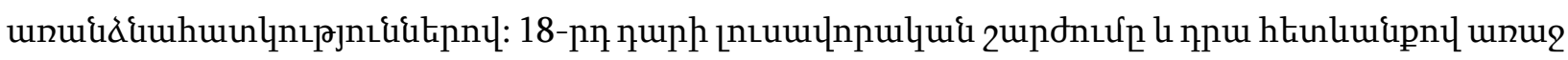

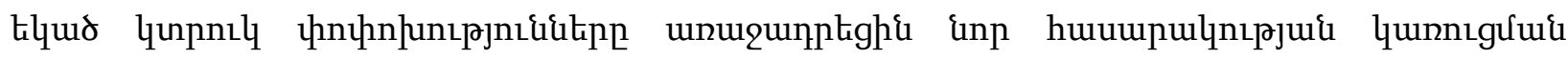

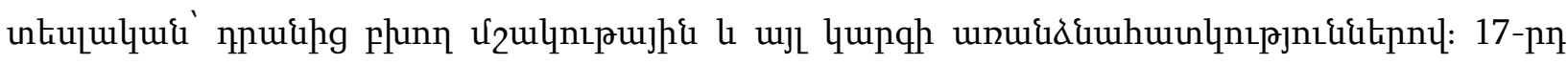

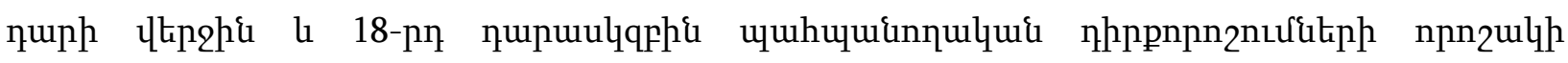

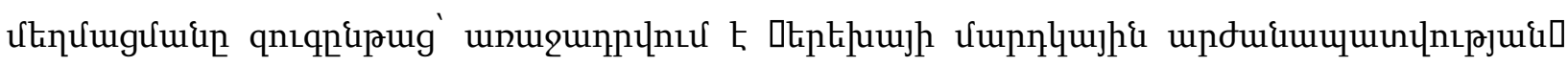

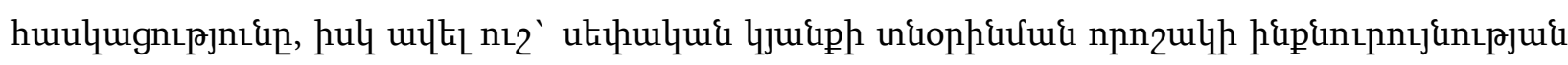
hpuulnz\&p:

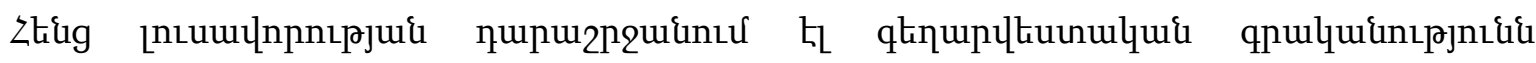

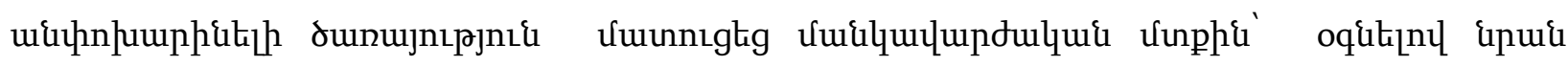

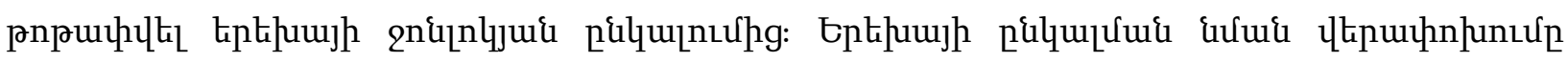




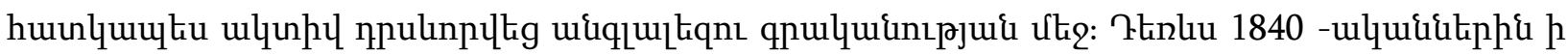

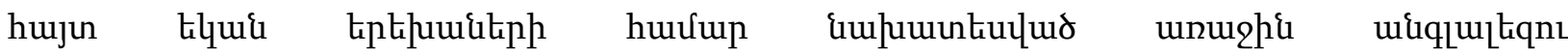

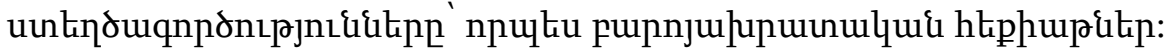

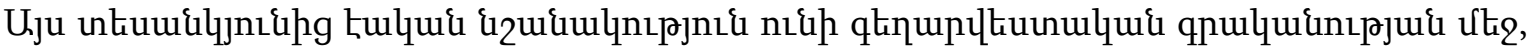

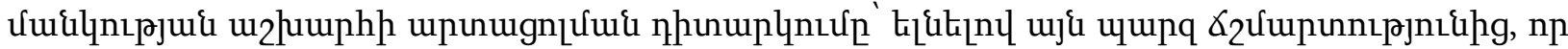

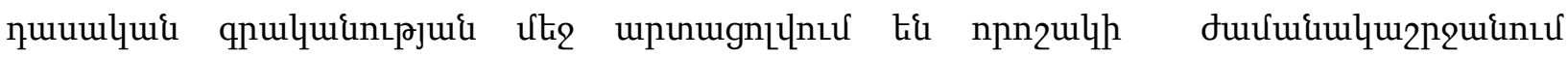

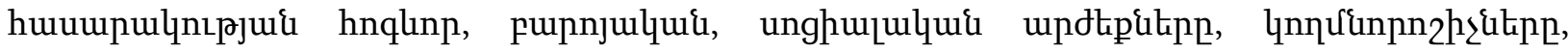

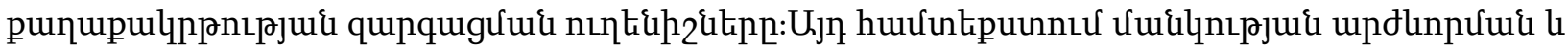

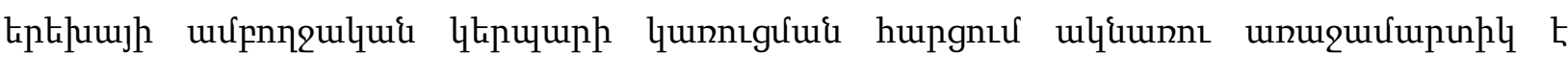

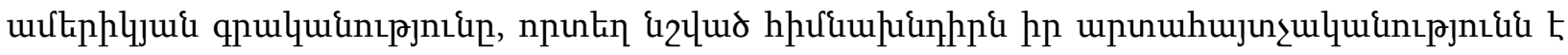

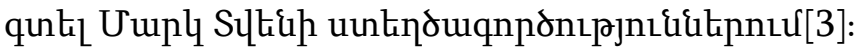

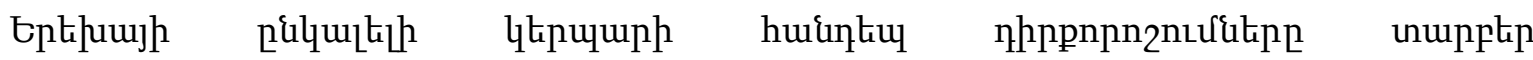

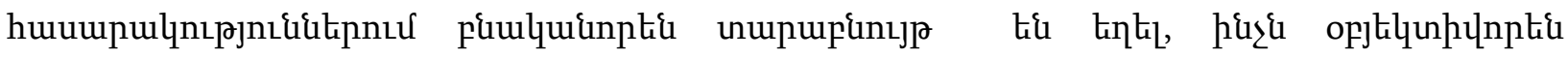

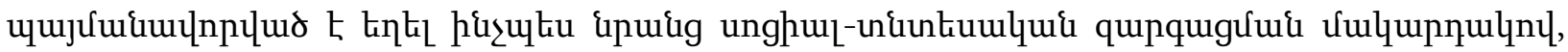

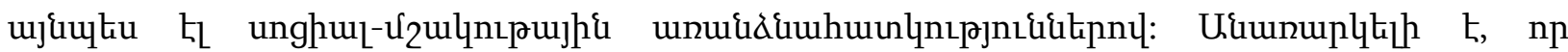

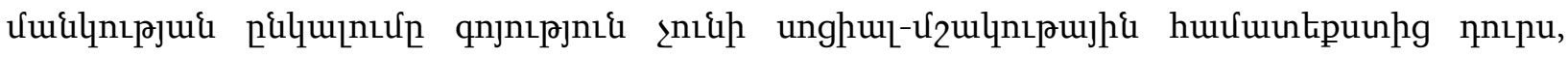

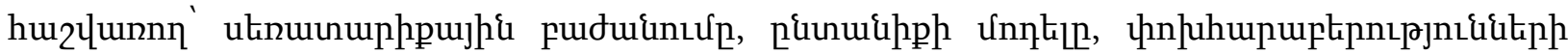

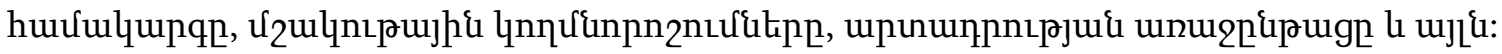

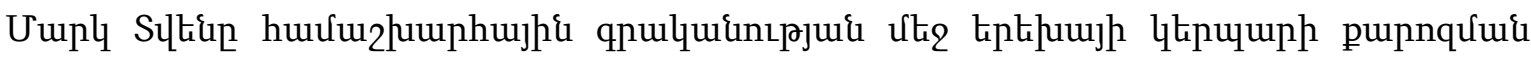

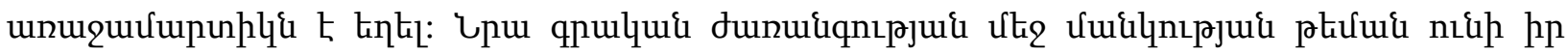

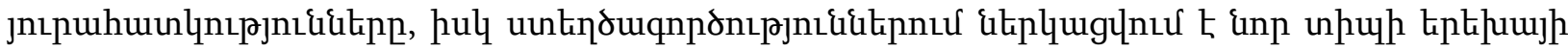

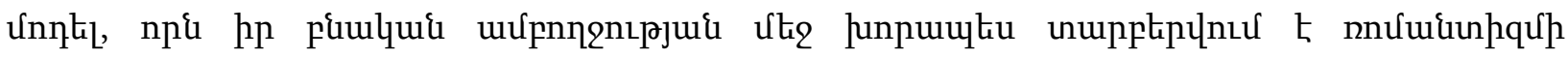

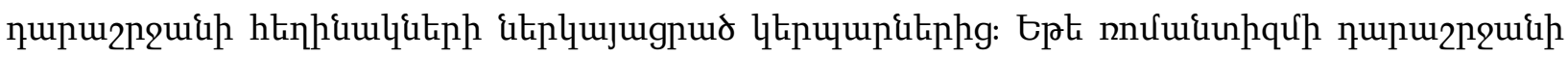

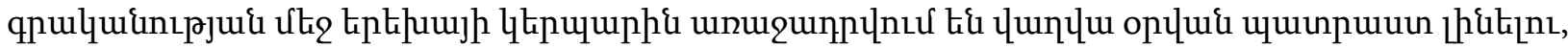

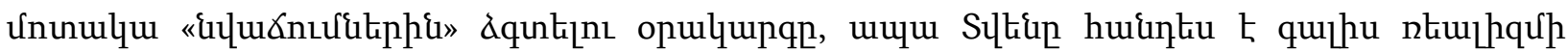

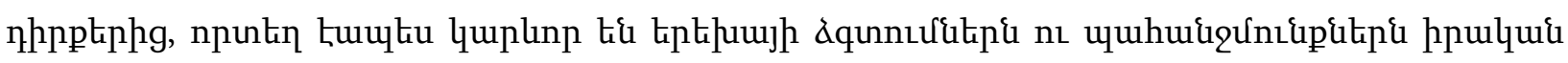

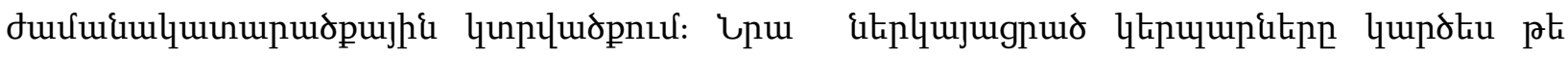

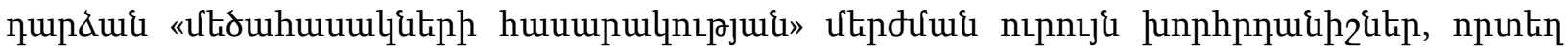

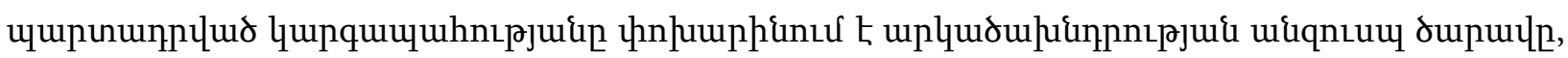

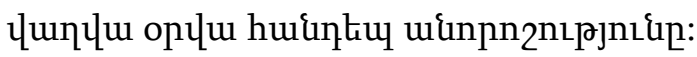

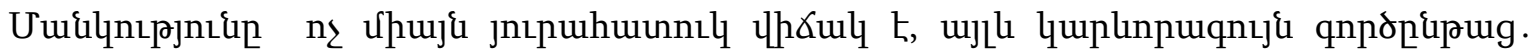

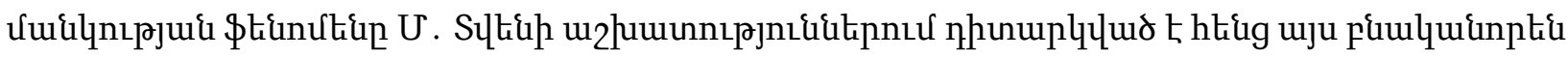

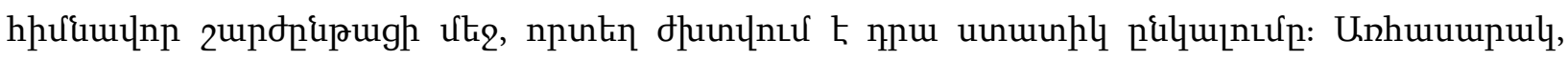




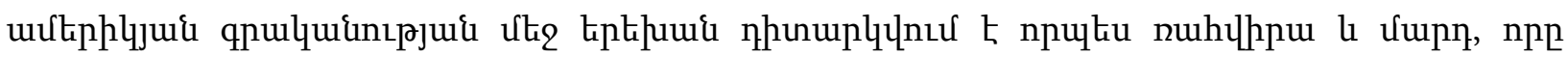

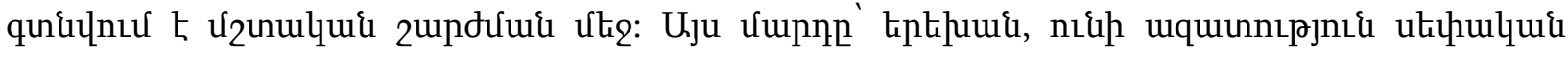

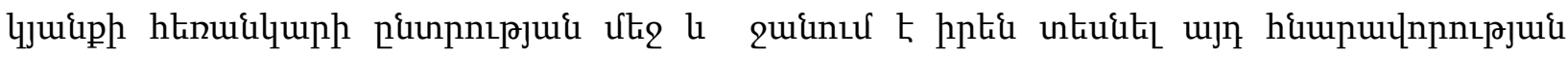
212uidulqutipnuf:

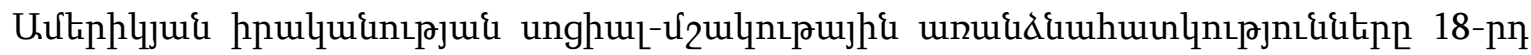

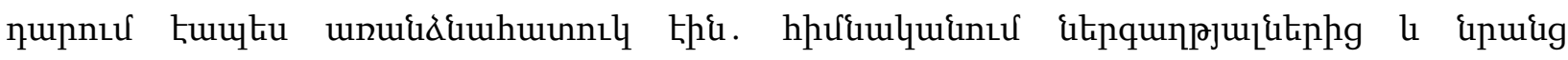

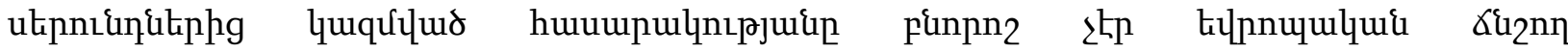

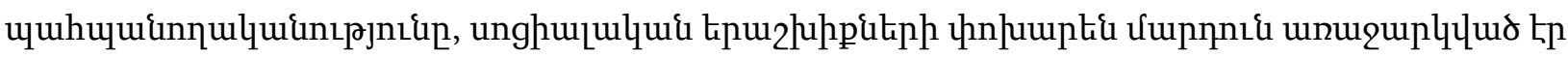

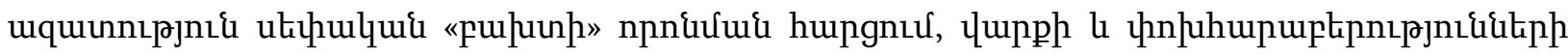

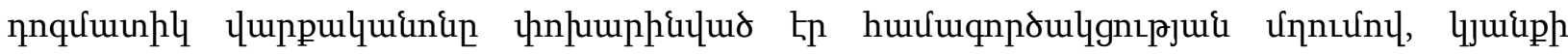

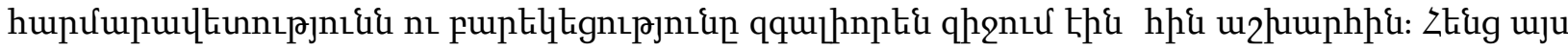

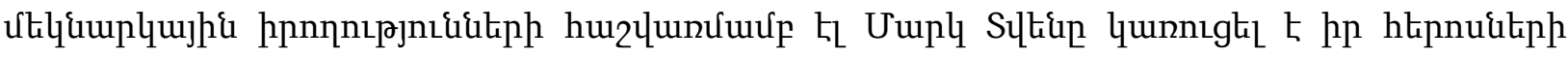

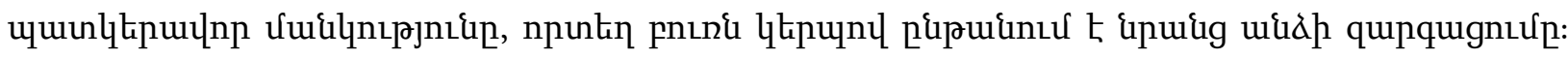

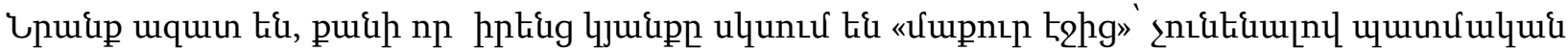

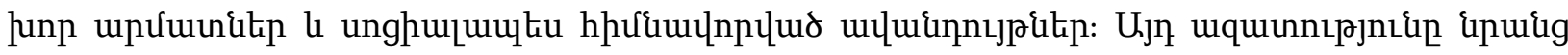

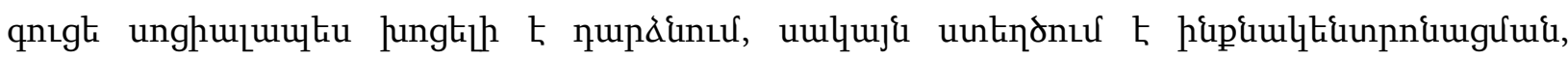

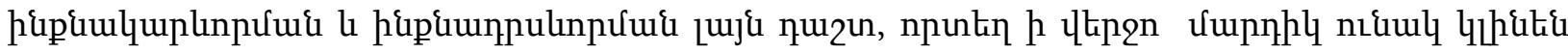

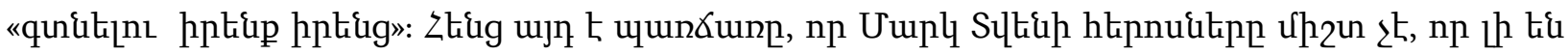

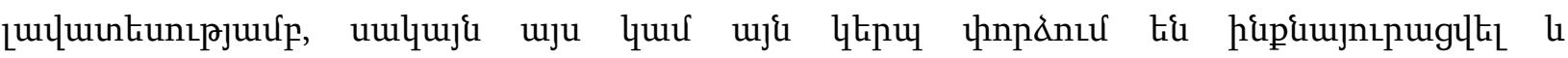

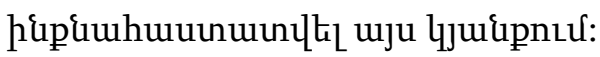

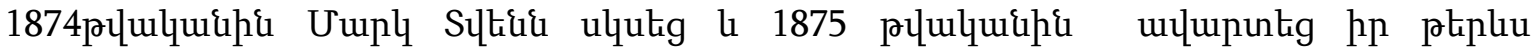

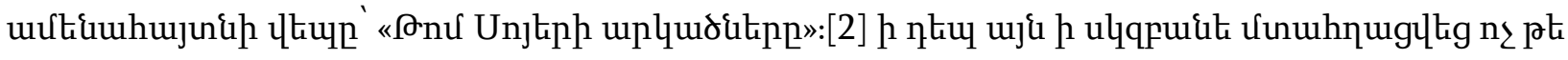

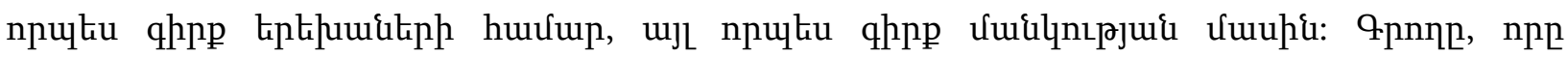

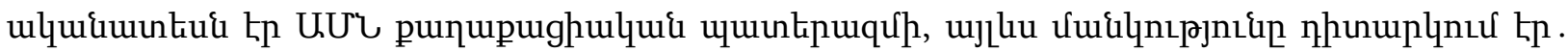

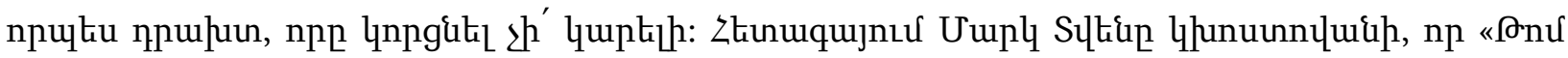

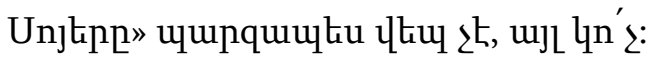

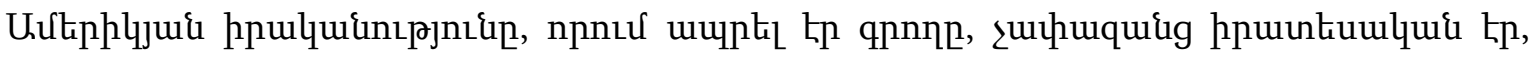

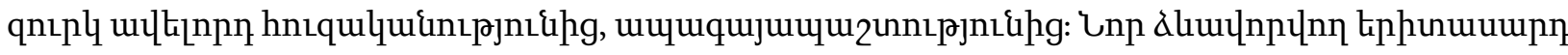

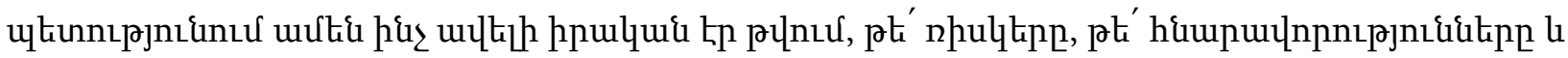

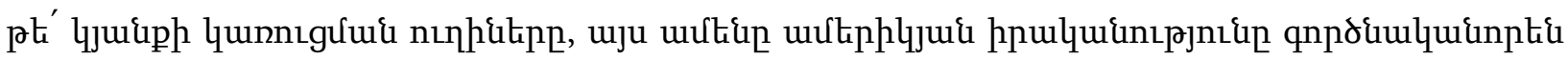

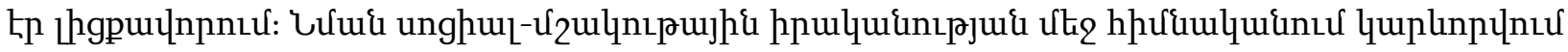

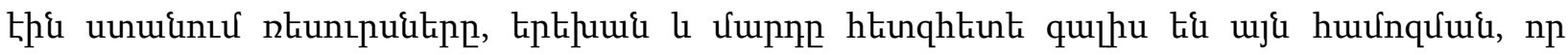

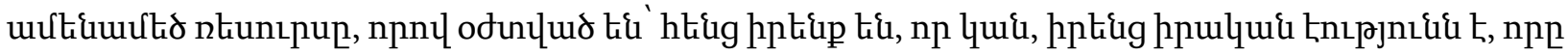


upkinp $\vdash$ puguhujunti la lhpuplik:

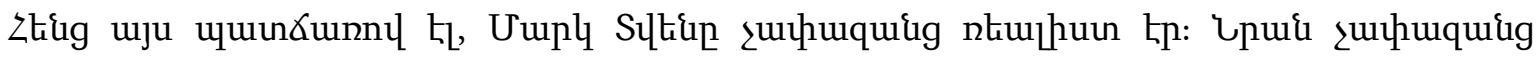

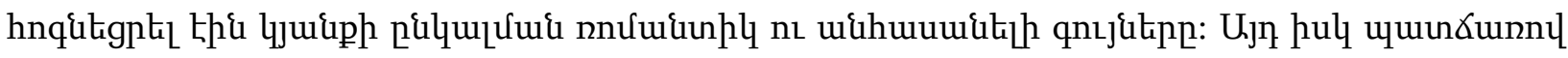

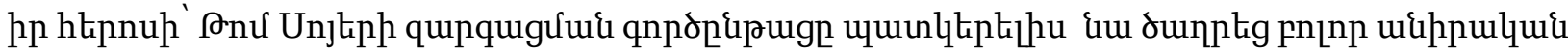

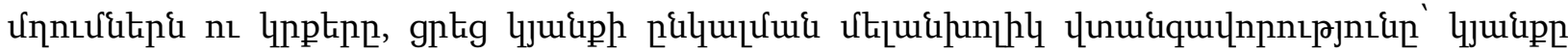

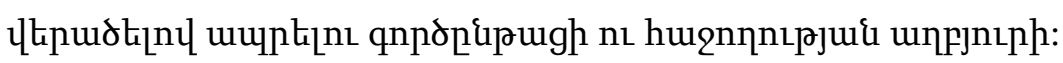

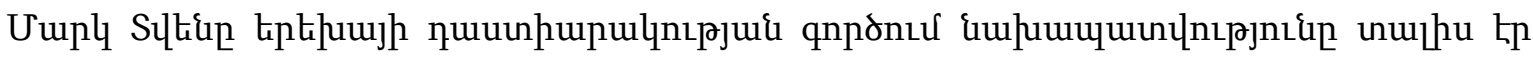

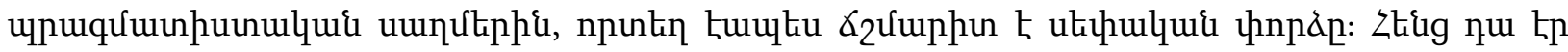

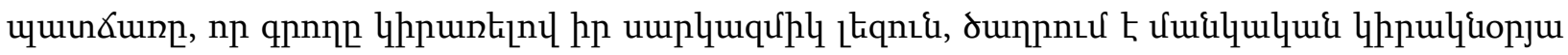

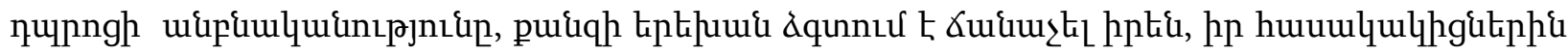

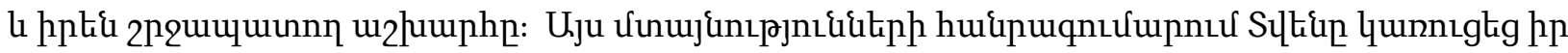

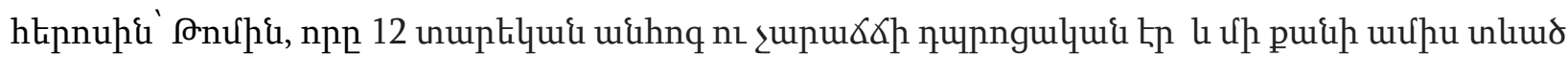

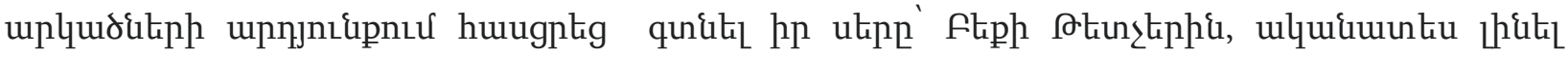

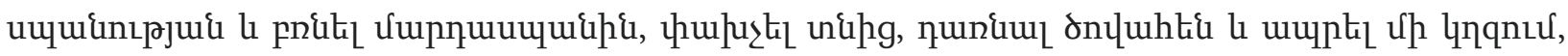

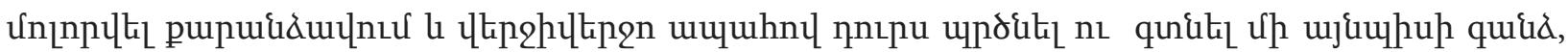

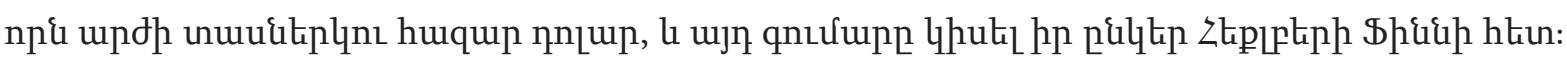

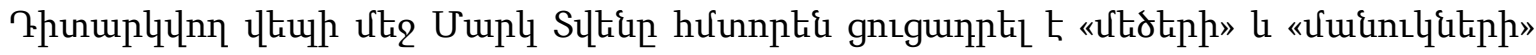

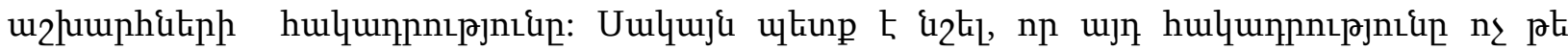

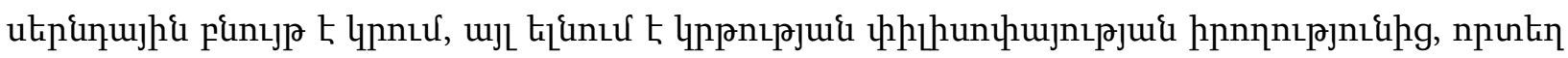

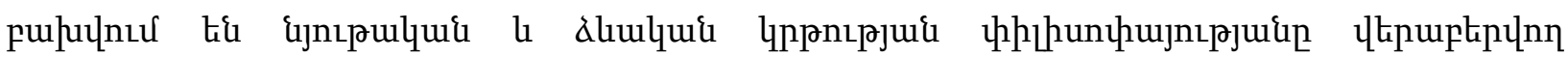

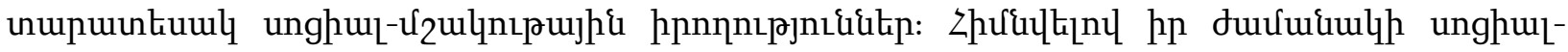

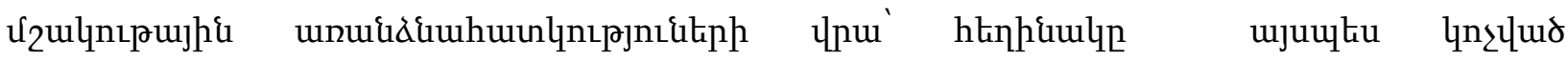

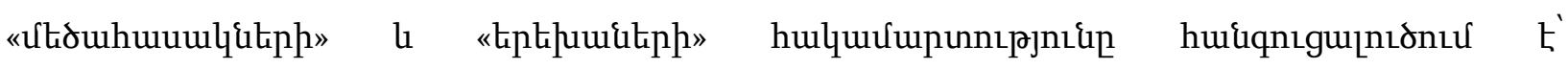

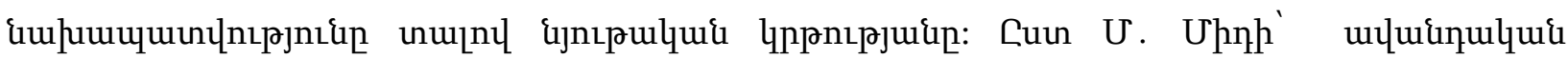

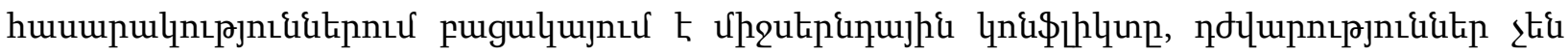

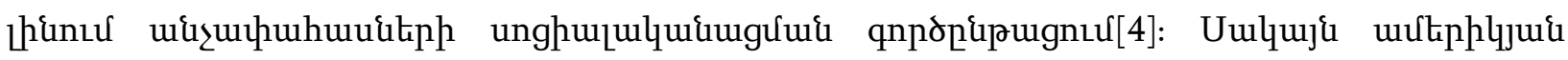

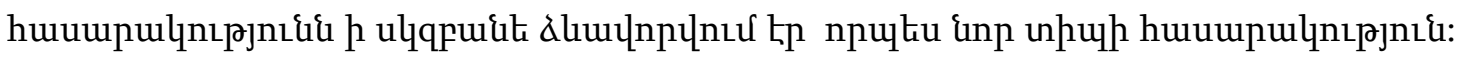

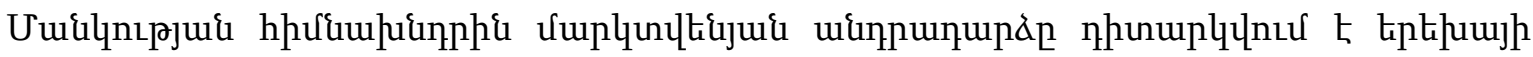

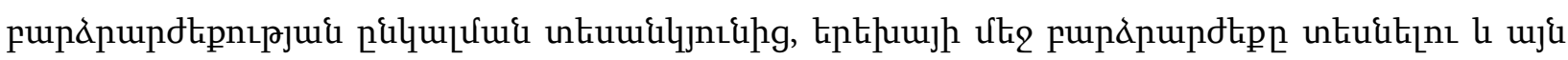

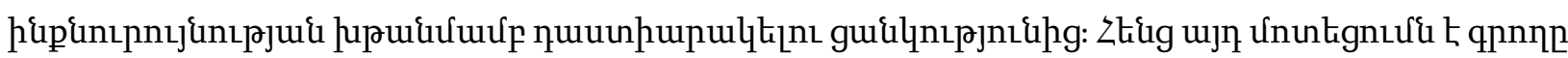

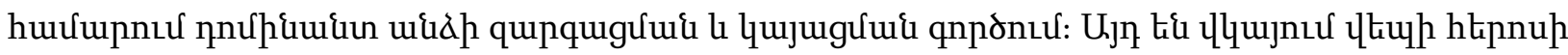

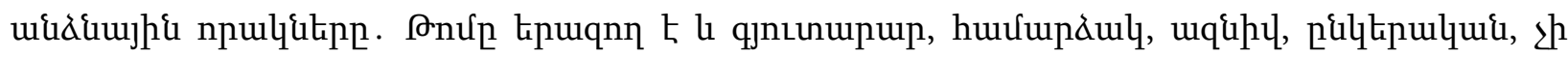

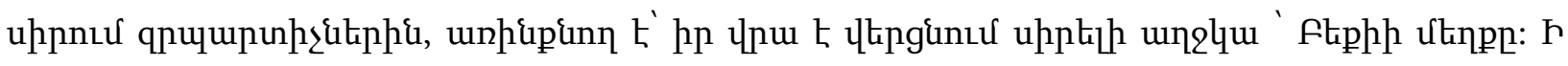




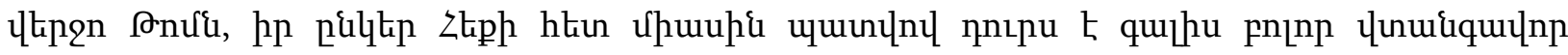

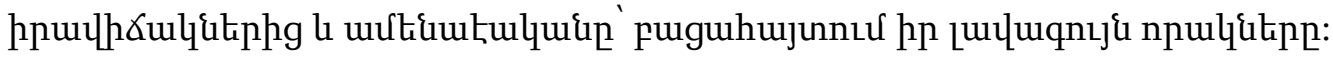

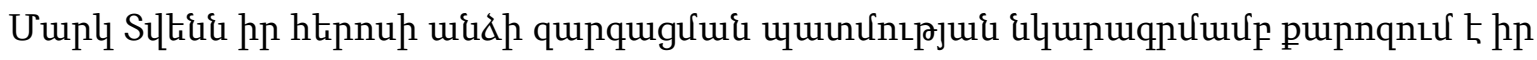

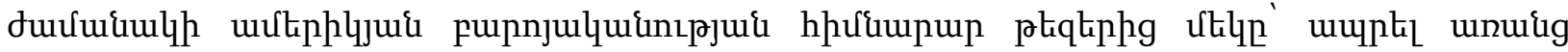

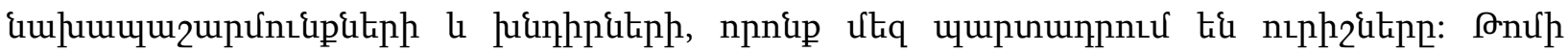

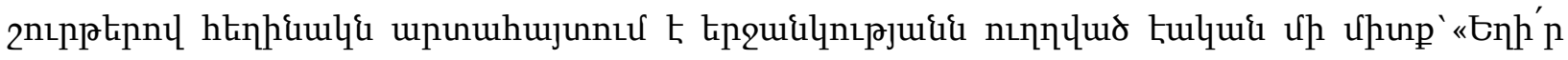

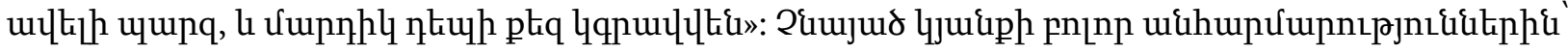

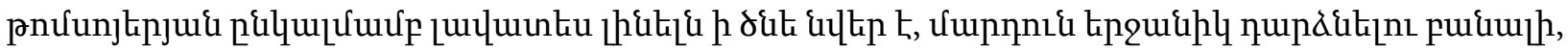

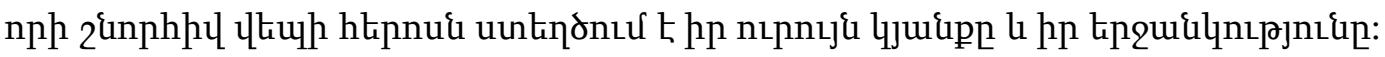

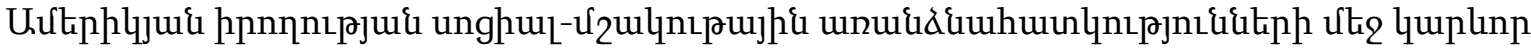

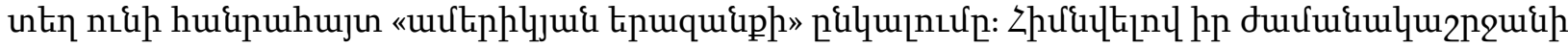

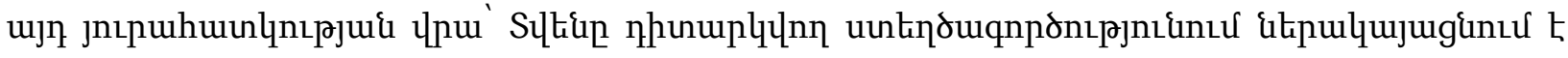

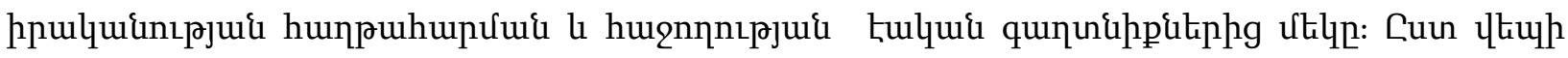

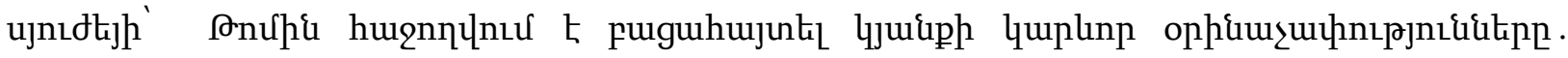

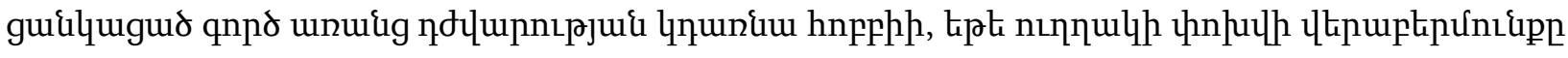

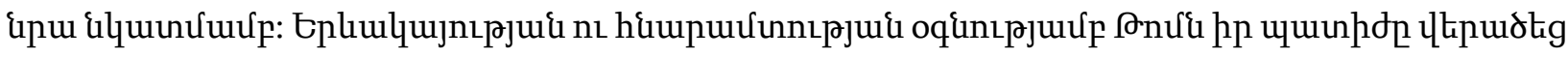

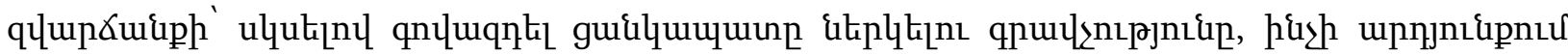

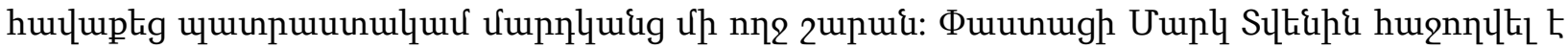

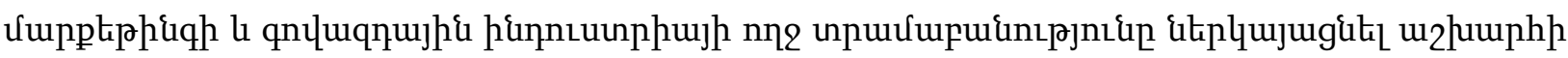

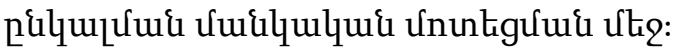

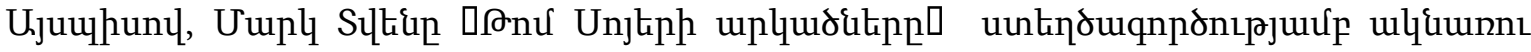

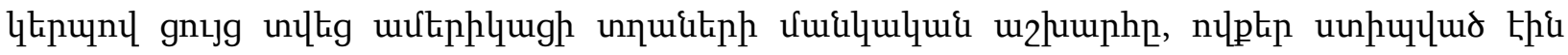

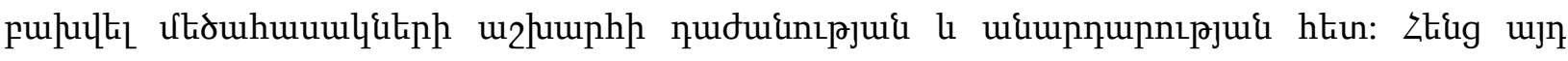

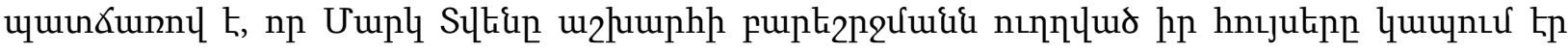

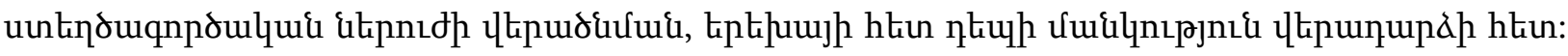

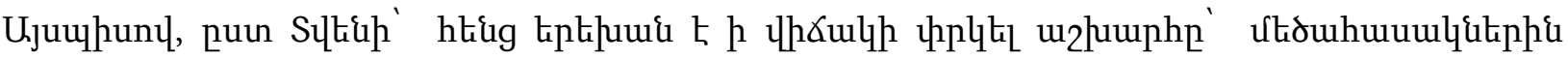

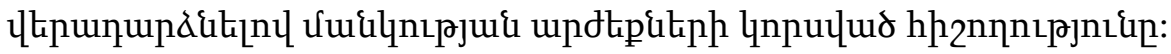

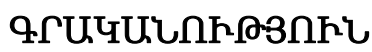

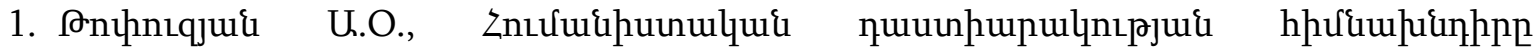

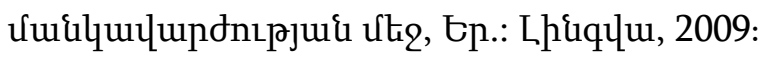

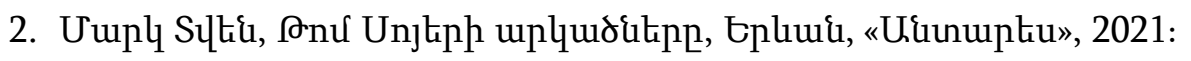


3. Зверев А.М. Марк Твен и его роль в развитии американской реалистической литературы. М., Наука, 1987.

4. Мид М.Культура и мир детства. М., Наука, 1988, 429с .

\section{THE RELATIONSHIP BETWEEN CHILDHOOD AND SOCIO-CULTURAL ENVIRONMENT IN MARK TWAIN'S WORKS}

The article examines the issues of childhood in the socio-cultural environment in the works of Mark Twain. Marktven's approach to the issue of childhood is viewed from the point of view of the child's perception of high value, the desire to see the high value in the child, to nurture it by promoting independence.

Keywords: Mark Twain, childhood, environment, upbringing, child, personality development, values, perception 